Monatsschrift f. Geburtshülfe u. Gynäkologie 1921;55:38-39

\title{
Wilhelm Tauffer
}

(2. Juli 1851-1921)

Die Monatsschrift bringt Herrn Tauffer zu seinem Jubeltage herzliche Wünsche und Grüße dar! Herr Tauffer ist als einer der erfolgreichsten Schüältesten Mitar-

ler Hegars un- beitern.

unterbrochen in Am 2. Juli

bahnbrechen- 1851 in Klau-

der Tätigkeit senburg gebo-

gewesen. Er hat ren, trat er nach

die Lehren der dem Universi-

Freiburger Sj£ tätsstudium in

Schule mit un-JÊE Budapest und

gewöhnlichem “ Wien. nachkur-

Erf olg in seinem zem Aufenthalt.

Vaterlande $\mathrm{zu} \mathrm{jH}$ bei Spiegelberg

fruchtbarerVer- $\mathrm{H} \quad \mathrm{j} \Lambda$ in Breslau, bei

breitung go- Æê Hegar in Frei-

bracht! Er ge- $\wedge Æ \quad$ burg in eine As-

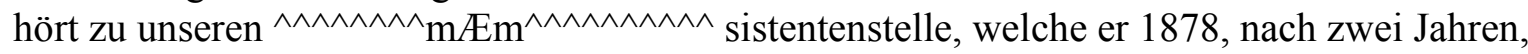
verließ, als sein Vaterland gegen Bosnien mobilisierte.

Alsdann trat Herr Tauffer in die damals von Kézmarszky geleitete Budapester Universitätsklinik ein, um sich gleichzeitig an der Universität zu habilitieren.

Wilhßlm Tauffer (2. Juli 1851-1921). 39

Kézmarszky erkannte die hohe Begabung Tauffers rückhaltlos an, indem er ihm alsbald eine Abteilung für Gynäkologie in der Frauen-klinik einrichtete. Hier konnte T. die epochalen Errungenschaften, $\bullet$ die er an den deutsehen Universitäten kennen gelernt hatte, zur vollen Wirkung bringen. 1881 w $\mu$ rde ihm ein zweiter Lehrstuhl für Geburts-hilfe und Gynäkologie an der Budapester Universität eingerichtet: der kaum Dreißigjährige wurde zum Ordinarius befördert. Das große Arbeitsfeld, welches sich ihm nunmehr eröffnete, hat er benutzt, um in Ungarn die Gynäkologie aus den Händen der Chirurgen zu einem selbständigem Fache zu entwickeln und zugleich eine bahnbrechende Tätigkeit als moderner Geburtshelfer zu entfalten. In kurzer Frist scharte sich eine große Zahl eifriger Schüler um ihn, so daß er, als er nach 37 jähriger Lehrtätigkeit im Jahre 1918 seine Stellung aufgab, eine Schule geschaffen hatte, welche heute der Gynäkologie im Ungar-land eine so hohe Stellung verschafft hat. Nach dem er sich vom Lehr-amt zurückgezogen, hat er sich gemeinnützigen Arbeiten gewidmet, die Säuglingspflege und den Mutterschutz maßgebend und ungemein erfolgreich organisiert. Tauffer hat in Gemeinschaft mit seinem Schüler und späteren Nachfolger Tóth ein vorbildliches Handbuch der Gynäkologie ge-schrieben; er hat selbst in einer großen Zahl von kleineren und größeren Mitteilungen die Erfolge seiner Studien und Forschungen bekannt-gegeben, die u. a. 
auch in den von ihm herausgegebenen ,Abhandlungen aus dem Gebiete der Geburtshilfe und Gynäkologie" niedergelegt sind. Vor alien Dingen hat er aber auf die große Zahl seiner auch akademisch tätigen Schüler einen nachhaltigen Einfluß ausgeübt. - Velíts, der unlängst verstorbene Professor, Dirner, Kubínyi, Frigyesi, Scipiades, Schmidtlechner und die Direktoren der ungarischen Hebammenschulen nennen ihn mit lebhaftem Dank ihren Führer und Lehrer. Schüler und Verehrer widmen ihm heute eine ungarische Festschrift, welche in der Julinummer der , Ärztefortbildungs-Zeitschrift” ungarisch erscheint. Wir wollen besonders dessen gedenken, daß Tauffer in treuer freundschaftlicher Anhänglichkeit den deutsehen Gynäkologen alle Zeit nahe gestanden hat. Nur selten fehlte er in unseren Ver-sammlungen. Fast alljährlich führte ihn seine Erholungsreise nach Deutschland. Die Deutsche Gesellschaft für Gynäkologie hat ihn seinerzeit durch die Berufung in den Vorstand geehrt.

Die Monatsschrift schließt sich an in dem Wunsche, Tauffer zu huldigen und unsere Verehrung und Zuneigung zu bekunden! Möge er noch lange sich der Früchte seiner rastlosen Arbeit erfreuen und der Freundschaft, welche er uns in seinem gesegneten Leben bewahrt hat. Wir erwidern sie herzlich!

A. Martin, A. Döderlein, L. Seitz, Ed. Martin.

Personalien.

Herr Professor Dr. Ernst Sachs in Berlin hat die Leitung der geburts-hilflich-gynäkologisehen Abteilung des dem Verbande der Krankenkassea gehörigen Krankenhauses in Lankwitz übernommen. 